\title{
Pervasive Marketing Intelligence
}

\author{
T. Guarda, M. F. Santos \\ ALGORITMI Centre \\ Minho University \\ Guimarães, Portugal
}

\author{
F. M. Pinto \\ Polytechnic Institute of Leiria \\ Portugal
}

\section{RESEARCH AND OUTPUTS}

\begin{abstract}
In the absence of sufficient and useful literature in the area of Marketing Intelligence Systems (MKTi), this study seeks to propose and infers aMKTi conceptual framework, through consensus, of a group of information systems (IS) and Marketing system experts. This research assumes that expert opinion can be of significant value in situations where knowledge or theory is incomplete, as in the case of MTKi systems in a Pervasive Business Intelligence (PBI) context. The Delphi method is used to conduct this study; this method is particularly suitable for this research situation where personal contact is not desirable among participants, annihilating the existence of opinion leaders, and ensuring democratic participation. This paper intends to take that first step in filling a gap in the MKTi, by proposing a conceptual framework for Marketing Intelligence systems in the context of PBI systems.
\end{abstract}

Keywords-business intelligence systems; pervasive business intelligence; marketing intelligence; pervasive marketing intelligence; delphi method

\section{INTRODUCTION}

In the business world, knowledge comes from information, and the information comes to the data. Knowledge assists managers in making timely and assertive decision. In any organization, it is critical to have a good understanding of the internal environment (processes, products, services, employees, customers, suppliers, and partners) and external of it (competitors, stakeholders, regulatory authorities). The rapid growth in the volume of information in organizations may become a problem due to lack of capacity to handle this information. Data is raw and unorganized, while information is the result of organized, structured and processed data.

At present, organizations are faced with an aggressive competitive environment, which will make difficult to maintain competitive advantage. According Guarda et al.[1]competitive advantage can be understood as seeking unique opportunities that will give the enterprise a strong competitive position.

Marketers and analysts need to dig deep into their data in order to rightly understand the impact of marketing campaigns, in order to be successful, the operationalization of BI throughout the organization is required, enabling business intelligence systems (BI) reach all levels of the organization, at the right time and with the necessary information [2], being pervasive.

\section{A. Motivation}

In recent years, global growth slowed, markets have matured and become more competitive. For many organizations, the only way to grow is at the expense of its competitors [3]. Companies are dependent on the evolution of marketing, to better adapt their strategies [4]. This study crosses several areas; it is intended the construction of a framework for integration of Marketing Intelligence in the Pervasive Business Intelligence systems, providing greater flexibility in adapting to changes in business and information needs, and providing better support for marketers in the decision-making process.

\section{B. Research Objective}

The research problem was identified considering the needs of marketer's to have information to support timely decision, allowing them to be proactive and face competition, and the capabilities of PBI, that enable BI systems reach all levels of the organization, at the right time and with the necessary information.

The objective of this research is to develop a conceptual framework to assist marketers in decision making process, leveraging various technologies, strategies, and resources for sustainable innovation.

Given the complexity of MKTi and its integration into PBI systems, it is intended exploit the best form to improve the approach of MKTi to PBI, taking the first step to the pervasive mark etingint elligence (PMKTi).

\section{Methodology}

The Delphi method was used for gathering and analyzing data for this study. We apply the Delphi method to assess the proposed framework. This method is suitable as a research tool in incomplete knowledge of situations on a phenomenon or problem, but it is not suitable for all kinds of problems in IS and works well when the goal is to improve the understanding of the problems, opportunities, solutions, and also develop forecasts.The Delphi methodology is used for the identification of future events and trends, operationalized by consulting a group of experts. The Delphi method is one of the most popular qualitative methods, is effective as structured and independent surveys of experts do not provide biased estimates of alternative futures [5]. This is a decision-making method in a group that is characterized by the fact that each member of the group present their ideas independently, each element isolated from the rest of influence. Many variations of 
the Delphi method have been used in the fields of information $[6,7,8,9,10]$.

To do this, we invited experts from different areas with interests in the areas of BI, PBI and MKTi such as companies in the area of information technology, online sales companies, teachers, and researchers. On the $1^{\text {st }}$ round 21 candidates agreed to read de framework description and give feedback to the presented questions. The final expert panel is composed by 21 personalities, which are distributed in different areas: information technology companies;online sales companies; marketing researcher and information systems researcher. All the communication process with the expert panel was made by e-mail. Whole process was conducted in the absence of any dialogue between members of the expert panel.This qualitative research was developed by questionnaire, through a set of multiple choice questions and open questions questionnaire.

\section{DESCRIPTIVE FRAMEWORK DIMENSIONS}

There is no a generic model for PBI implementation success, and one of the reasons is the fact that different implementations processes are unique in their own way. In spite of its complexity, we can see the PBI as a framework for organizing the data, information management and tools and technologies that are used to build BI across all organizational departments, for reporting and data analytics[11,12], and when it's well implemented produces positive results for the end users[13].

The process for satisfying user's information needs is complex and composed by different activities to be exploited. The propose framework has been designed primarily to assess the outputs of qualitative inquiry (Fig.1), and comprises three dimensions: data in, data storage and data out.The $1^{\text {st }}$ dimensiondefines theinformation needsof theend user.Thenin the $2^{\text {nd }}$, based on the information requirementsdefined in the previousdimension, data is acquiredfrom multiplesources (internal and external), extracted,cleanedandtransformed into information. Finally, in the $3^{\text {rd }}$ dimension, are usedanalytical toolsthat transforminformation into knowledge that will bedelivered to theend user forevaluation and possiblefurtherfeedbackif necessary,representinga three-dimensionaliterativecycle. The cycle begins again or continues, as the information needs until the decision makers meet their needs appropriately.

The first dimension is leveraged by the process mining (PM) for evaluation and suitability of process models to the requirements defined in the planning of necessary decision making information. Then the collection process, oriented by the appropriate process model, extract, transforms and load (ETL) organization internal and external data sources, and that include CRM, prospects data, market data and competition. The ETL is a process for extracting data from a database system, where the data are processed, modified, and then inserted into another database $[14,15]$. In the second dimension, data from the first dimension are loaded, organized and coded information on the data warehouse data marts, specifically in marketing data mart, and is made available fordirect querying. The metadata provides transparency as data moves from sources to the warehouse, and from DW to end users [13], and helps to create a common way of describing information assets across the organization, integrating the several metadata models in use in organization.

In the third dimension, the data access and analysis process, access marketing datamart applying the marketing metadata models to process organization reporting, querying,and other analytical and predictive applicationsfor representing information from marketing perspective, and the results, or valuable intelligence produced [11], will be distributed to endusers (marketers) for review andposterior feedback if needed, and the results mustbe clearand understandable enough for the required decision-makers [16].

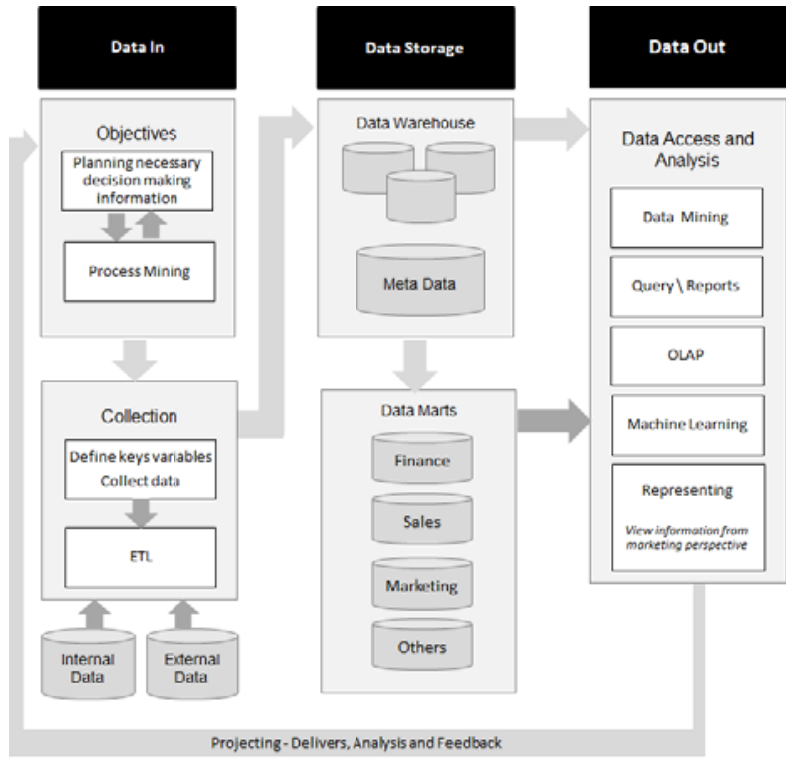

FIGURE I. PERVASIVE MARKETING INTELLIGENCE FRAMEWORK

\section{ExPert PANEL EVAluation}

The Delphiprocesswas appliedin three rounds. In order to close each interaction with expert panel members, after all answers received, we have made a resume and which then was validated by the expert panel. The objective of the $1^{\text {st }}$ round was to test the desirability and feasibility of the framework, the questionnaire was designed to evaluate framework in terms of its comprehensiveness, conciseness, completeness, applicabilityand usability.We used the 5 points Likert scale (1. Strongly disagree, 2. Disagree, 3. Neither agree nor disagree, 4. Agree, 5. Strongly agree). Analysing the reaction of participants $(n=21)$, it was found that $38.10 \%$ do not agree with the structure of the three dimensions, arguing that the 2 nd and 3rd dimension complement each other, not being necessary for their division. Regarding the general assessment of the framework, were not detected major reservations.Based on Cronbach's Alpha, $\alpha=.829$, it can be concluded, that results indicates good reliability.It should be noted that an alpha of .8 is probably a reasonable goal.In the $2^{\text {nd }}$ round, we sent the results to the participants, and have been sent a new questionnaire to evaluate the processes that compose each of the three dimensions, in terms of completeness, correctness, maintainability, interactivity, accuracy.After analysing the results, in the analysisof alldimensionsit was verified that $\alpha$ $=.848$, reflectinga slight increase, and values perdimensiondo 
notexhibit greatvariance $(\alpha=.897 ; \alpha=.888 ; \alpha=.724)$. The consensusholds upamong the participants. In the last round, the results were sent to participants, leaving open the possibility of revising. Nofurtherchangeswere observed.

\section{CONCLUSION}

This research was achieved through exploring some prospective information systems areas, strategic factors, and measuring related judgments from expert panels. This study develops a research framework that can assist decision makers in emerging economies. This theoretical framework should be followed for implementing PMKTi as an enabler for their competitiveness. The participants in this Delphi process achieved consensuson a generic quality criteria list. The adoption of this core set by the expert panel may be the first step toward a minimum reference standard of quality measures, for the framework quality criteria.

\section{ACKNOWLEDGEMENTS}

This work has been supported by FCT -Fundaçãopara a Ciência e Tecnologia within the Project Scope UID/CEC/00319/2013.

\section{REFERENCES}

[1] T. Guarda, M. Augusto, and C. \& Silva, "Competitive advantage in ecommerce: the case of database marketing," in In Business, Economics, Financial Sciences, and Management, 2012, pp. 123-130.

[2] T. Guarda, M. F. Santos, F. Pinto, C. Silva, and J. Lourenço, "A Conceptual Framework for Marketing Intelligence," Journal of $e$ Education, e-Business, e-Management and e-Learning (IJEEEE), pp. 455-459, 2012.

[3] David A. Aaker, V. Kumar, George S. Day, and Robert Leone, Marketing Research, 10th Edition.: Wiley.com, 2009.

[4] N. K. Malhotra, Pesquisa de marketing: uma orientação aplicada. Bookman, 2012.

[5] Stephen A. Delurgio, Forecasting principles and applications. Singapura: McGraw-Hill, 1998, ISBN 978-0-07-115998-2.

[6] James C. Brancheau, Brian D. Janz, and James C. Wetherbe, Key issues in information systems management: 1994-95 SIM Delphi results, pp. 225-242, 1996.

[7] Roy Schmidt, Lyytinen Kalle, and Paul Cule Mark Keil, "Identifying software project risks: an international Delphi study," Journal of management information systems, vol. 17.4, pp. 5-36, 2001.

[8] Paul Mulligan, "Specification of a capability-based IT classification framework," Information \& Management, pp. 647-658, 2002.

[9] Chitu Okoli and Suzanne D. Pawlowsk, "The Delphi method as a research tool: an example, design considerations and applications," Information \& Management, pp. 15-29, 2004.

[10] Tonia de Bruin and Michael Rosemann, "Using the Delphi technique to identify BPM capability area," in ACIS 2007 Proceedings, vol. 42, 2007.

[11] V. Pirttimäki, Business intelligence as a managerial tool in large Finnish companies, 646th ed., Publication, Ed.: Julkaisu-Tampere University of Technology, 2007.

[12] Kjell Borking, Transcending Business Intelligence.: Sine Metu Productions, 2011.

[13] H.J. Watson and B.H. Wixom, "The current state of business intelligence," Computer, vol. Vol. 40, pp. 96-99, 2007.

[14] A. Weijters and WMP Van der Aalst, "Process mining: discovering workflow models from event-based data," in Proceedings of the 13th Belgium-Netherlands Conference on Artificial Intelligence, 2001, pp. 283-290.

[15] Wil MP. van der Aalst, Process mining." Encyclopedia of Database Systems.: Springer, 2009.
[16] Jr. JH. Thomas, "Business intelligence-why?," eAI Journal, pp. 47-49, 2001. 